\title{
Communications
}

\section{Descriptions de quelques genres nouveaux de l'Ordre des Araneae}

\author{
par E. Simon.
}

Paractroplnios, nov. gen. - A Strophio differt area oculorum mediorum paulo longiore quam latiore et antice quam postice multo angustiore, abdomine longiore quam latiore, antice rotundo, postice sensim ampliato et obtuse prominulo.

P. echinosoma, sp. nov. \& long. 6 mill. - Cephalothorax coriaceus, parce nigro-setosus, fusco-rufescens, parte cephalica dilutiore luteo-variegata et trilineata, thoracica utrinque vittis radiantibus nigris abbreviatis notata, margine clypei setis brevibus 12 armato. Abdomen cinereum, rufulo-variatum, utrinque late albido-marginatum postice albido-segmentatum et maculis binis magnis nigris notatum. Chelae fuscae, setis spiniformibus brevibus hirsutae. Sternum pedesque obscure fulva, femoribus rufulo-punctatis, tibiis metatarsisque anticis late fusco-annulatis. - Africa occid. : Cameroon.

Emplesiogonus, nov. gen. - A Pseudoporrhopi differt oculis lateralibus utrinque parvis, aequis, nec tuberculatis nec prominulis, oculis mediis aream saltem quintuplo latiorem quam longiorem occupantibus, posticis minutissimis, abdomine magno, antice obtuso, postice ampliato et obtuse truncato.

E. striatus, sp. nov. \& long. 4 mill. - Cephalothorax nigricans, confuse fusco-rufulo-marmoratus, ad marginem clypei late testaceus, crebre granulosus et albido-pilosus. Abdomen fulvo-testaceum, breviter flavido-pilosum, leviter fusco-variatum et postice lineolis transversis nigris segmentatum. Chelae, partes oris, sternum coxaeque nigra. Pedes brevissimi, breviter pilosi, albido-testacei, femoribus ad apicem tenuiter nigro-cinctis, patellis nigro-lineatis. - Nossi-Be.

Diplotychus, nov. gen. - A Phaenopomati differt cephalothorace humili, paulo longiore quam latiore et antice quam postice angustiore, clypeo oculis lateralibus anticis (mediis fere quadruplo majoribus) latiore, pedibus anticis longioribus et gracilioribus; A Lycopodi et Scoptico differt oculorum linea antica recta. 
D. longulus, sp. nov. क (pullus) long. 4 mill. - Fulvo-testaceus, tuberibus oculorum lateralium nigris. Abdomen angustum et longum, antice truncatum. Pedes antici longi, femore $1^{\mathrm{i}}$ paris aculeis tenuibus longissimis et erectis trinis intus munito, tibia metatarsoque aculeis similibus 3-3 subtus instructis, tibia aculeis binis nigris temuibus sed leviter lanceolatis et metaturso aculeo simili submedio, intus armatis. - Madagascar : Antongil (Mocquerys).

Iphoctesis, nov. gen. - A Trichopagi differt area oculorum mediorum longiore quam latiore et antice quam postice paulo latiore, oculis mediis posticis minutissimis, chelarum margine inferiore mutico, tarso pedum-maxillarium feminae haud dilatato.

I. echinipes, sp. nov. † long. ə̈ mill. - Cephalothorax nigellus, vitta media dilutiore, postice dentata, notatus, coriaceus, pilis brevibus fulvis obtusis vestitus, et tuberculis subrotundis rufulis conspersus, area oculorum in medio tuberculis geminatis binis conicis armata, margine clypei setis seriatis longissimis 8 munito. Abdomen longius quam latius, postice sensim ampliatum, fusco tesiaceum, subtus late dilutius, supra pilis obtusis luteis vestitum et tuberculis longe spiniferis conspersum. Chelae nigrae, laeves, intus ad basin aculeis 4-5 armatae. Sternum laeve, fulvum, ad marginem infuscatum. Pedes fulvi, valde et late nigro fuscoque annulati, femoribus patellis tibiisque anticis tuberculis spiniferis paucis supra armatis, tibiis metatarsisque subtus biseriatim aculeatis. - Madagascar : Antongil (Mocquerys).

Tan rana, nov. gen. - Ab Anyphaena differt tibiis anticis aculeo parvo medio interiore, metatarsis anticis, usque ad basin scopulatis, aculeis basilaribus binis tantum armatis, tegumentis corporis et artuum setis longis obtusis et erectıs conspersis.

T. Riveti, sp.nov. + long. 13 mill. - Cephalothorax fusco-castaneus subtiliter coriaceus. Abdomen luteo-testaceum, nigricanti-functatum, postice sensim infuscatum. Chelae nigrae, validae et longae, margine superiore sulci dentibus remotis binis $1^{\circ}$ majore, inferiore dentibus parvis et obtusis 4, armatis. Pedes fulvo-rufuli, antici vix obscuriores. Plaga genitalis fusca, rugosa et pilosa, fovea transversa triquetra impressa. - Ecuador : Troya (Dr Rivet). 


\section{$2 \mathrm{BHL}$ Biodiversity Heritage Library}

Simon, Eugène. 1903. "Descriptions de quelques genres nouveaux de l'ordre des Araneae." Bulletin de la Société entomologique de France 1903, 123-124.

View This Item Online: https://www.biodiversitylibrary.org/item/104431

Permalink: https://www.biodiversitylibrary.org/partpdf/41657

\section{Holding Institution}

Smithsonian Libraries

\section{Sponsored by}

Smithsonian

\section{Copyright \& Reuse}

Copyright Status: NOT_IN_COPYRIGHT

This document was created from content at the Biodiversity Heritage Library, the world's largest open access digital library for biodiversity literature and archives. Visit BHL at https://www.biodiversitylibrary.org. 